\title{
A challenge to the seven widely believed concepts of COPD
}

\author{
This article was published in the following Dove Press journal: \\ International Journal of COPD \\ II January 2013 \\ Number of times this article has been viewed
}

\author{
Feisal A Al-Kassimi \\ Esam H Alhamad \\ Division of Pulmonology, Department \\ of Medicine, College of Medicine, \\ King Saud University, Riyadh, \\ Saudi Arabia
}

Abstract: This review proposes a critical reassessment (based entirely on published evidence) of the following seven common beliefs about chronic obstructive pulmonary disease (COPD): (1) COPD is one disease. (2) There is a valid definition for COPD. (The current definition includes cases of irreversible asthma and bronchiectasis, and occasionally, other obstructive lung conditions). (3) Irreversible asthma in smokers and COPD cannot be differentiated. (4) A "chronic bronchitis" form of COPD exists and is characterized by blue bloater status and normal carbon monoxide diffusion studies. (5) Phenotyping has no bearing on medication choice in COPD. (6) Computerized scoring of lung attenuation on CT scans can diagnose emphysema. (Emphysema scores overlap in irreversible asthma and COPD); however, qualitative visual changes may be useful for differentiation. (7) A definable entity called the overlap (of COPD and asthma) syndrome exists. Conflict over the abovementioned points denies patients proper phenotype-guided therapy and encourages a multidrug approach to COPD management. The recently coined term, overlap syndrome, invites a double-barreled therapy aimed at asthma and COPD, despite the absence of any agreement about how to define the syndrome and the lack of any related drug trials (in the area of inhaled corticosteroids). A diagnosis of COPD is associated with high morbidity and escalating costs, suggesting the need for a thorough new examination of the evidence.

Keywords: asthma, computerized tomography, COPD, global initiative for chronic obstructive lung disease, overlap syndrome

\section{How is COPD currently diagnosed?}

The Global Initiative for Chronic Obstructive Lung Disease (GOLD) defines COPD as "the presence of post-bronchodilator $\mathrm{FEV}_{1} / \mathrm{FVC}<0.70$ which confirms the presence of persistent airflow limitation and thus COPD," if associated with symptoms and/or history of exposure to risk factors. ${ }^{1}$ Even in nonsmokers, irreversible airway obstruction is sometimes called never-smoker COPD or NSCOPD, despite being largely attributable to asthma. ${ }^{2}$ Although all guidelines accept that irreversible asthma is an important differential diagnosis for COPD, even the most recent ones conclude that in some patients, the currently available physiological and radiological testing techniques are not able to make a clear distinction between the irreversible form of asthma and COPD. ${ }^{1}$

A substantial number of cases of irreversible asthma "masquerade" as COPD. Based on the clinical and physiological testing used to differentiate the two conditions, Bellia et al estimates that $20 \%$ of elderly COPD patients are suffering 
from irreversible asthma. ${ }^{3}$ However, this is likely to be an underestimate, and the mislabeling is not limited to the elderly. Irreversible obstruction is reported to occur in $23 \%$ of chronic asthmatics. ${ }^{4}$ A lengthy history of asthma and smoking is an important risk factor that increases the likelihood that asthma will become irreversible. ${ }^{4,5}$ Asthma has a prevalence of $10 \%$ to $12 \%$ in the general population, including the elderly. ${ }^{6-8}$ Therefore, it is expected that $2.5 \%$ to $3 \%$ of the general population (including smokers) suffers from irreversible asthma. Roughly translated, this indicates that one-third of all cases of COPD are actually asthmatic. This estimate is supported by two studies that utilized bronchial biopsy, computerized tomography (CT) scan, and physiological tests to differentiate irreversible asthma and COPD. ${ }^{9,10}$ The findings of these papers and the value of various techniques in differentiating irreversible asthma and COPD are discussed below.

\section{The role of bronchial biopsy in differentiating irreversible asthma and COPD}

Early studies concluded that bronchial biopsy could not differentiate asthma and COPD. However, these studies were performed on asthmatics with mild, reversible asthma. ${ }^{11,12}$ In the most important of these studies, the mean forced expiratory volume in one second $\left(\mathrm{FEV}_{1}\right)$ was $94 \%$ (range: $79 \%-100 \%$ ) in the asthmatic group versus 59\% (45\%-67\%) in the COPD group. ${ }^{11}$ Fabbri et al's landmark work on bronchial pathology used asthma and COPD patients with the same degree of fixed (irreversible) airways and mean post bronchodilator $\mathrm{FEV}_{1}$ values of $62 \%$ and $59 \%$, respectively. ${ }^{13}$ That study established the features that overlapped between the two conditions and those that were useful for differentiation. The basement membrane thicknesses were 6.6-9.7 $\mu \mathrm{m}$ in asthmatics and 4.2-6.2 $\mu \mathrm{m}$ in COPD patients. ${ }^{13}$ However, the other changes, such as asthmatics having higher eosinophil counts and $\mathrm{CD} 4_{+} / \mathrm{CD} 8_{+}$lymphocyte ratios in the bronchial wall, overlapped between the two conditions and were not useful for differentiation. ${ }^{13}$

\section{Clinical significance of histological differentiation}

The thickening of the reticular basement membrane in asthma results from extracellular matrix deposition, and is considered to represent an imbalance between collagendegrading metalloproteases (originating from eosinophils) and their inhibitors. ${ }^{14}$ Thickening of the basement membrane has been considered "characteristic for asthma while is not found in COPD." ${ }^{14}$ Even in reversible asthma (before thickness develops), the basement membrane is reported to have a different composition and staining properties from the basement membrane in COPD. ${ }^{12}$

In 1996, Chanez et al reported that 12 out of 25 (48\%) COPD patients had spirometric reversibility upon receiving prednisolone, and their bronchial biopsies demonstrated uniform thickening of the basement membrane. ${ }^{9}$ In 2011 , Al-Kassimi et al published a study where patients were divided into irreversible asthma and COPD groups on the basis of qualitative visual CT scan findings of panlobular emphysema with multiple bullas (Figure 1), the presence of hypercapneic respiratory failure with raised serum bicarbonate (never described in stable asthma), and bronchial histology. ${ }^{10}$ Figure $2 \mathrm{~A}$ and $\mathrm{B}$ show the histological criteria used to differentiate asthma and COPD. ${ }^{10}$ Table 1 shows the characteristics of both groups in that study.

There is some concern about whether the abovementioned methods have been validated to delineate two different clinical syndromes. In other words, did the patients in the COPD population diagnosed as asthma by bronchial biopsy behave clinically and physiologically like asthmatics? The studies are unanimous on the presence of a strong association or total concurrence between thickness of the reticular basement membrane and the following features: hypertrophy of the nasal turbinates, normal carbon monoxide diffusion capacity $\left(\mathrm{DL}_{\mathrm{CO}}\right)$, and response to oral prednisolone and inhaled corticosteroids (ICS). ${ }^{9,10,13}$

The clinical differentiation of asthma and COPD is of great importance. We have encountered heavy smokers with irreversible airflow limitation who were labeled as having COPD. The diagnosis was shifted to irreversible asthma based on normal transfer coefficient (KCO) calculated as carbon monoxide diffusion capacity/alveolar volume (DLCO/VA), and bronchial histology. Dramatic improvements in $\mathrm{FEV}_{1}$ and dyspnea were produced with the anti Ig-E therapy, omalizumab, a treatment that would not have been considered with the diagnostic label of COPD.

\section{Why carbon monoxide diffusion studies are not performed in COPD}

Numerous studies have documented that $\mathrm{DL}_{\mathrm{CO}}$ remains normal in severe or irreversible asthma unless there is concomitant bronchiectasis. ${ }^{4,15-17}$ Although $\mathrm{DL}_{\mathrm{CO}}$ and $\mathrm{KCO}$ were found to be reduced in emphysema, $\mathrm{KCO}$ correlated better with the high resolution computerized tomography (HRCT) scoring of emphysema. ${ }^{18,19}$ Several studies have documented the specificity of $\mathrm{DL}_{\mathrm{CO}}$ in diagnosing 


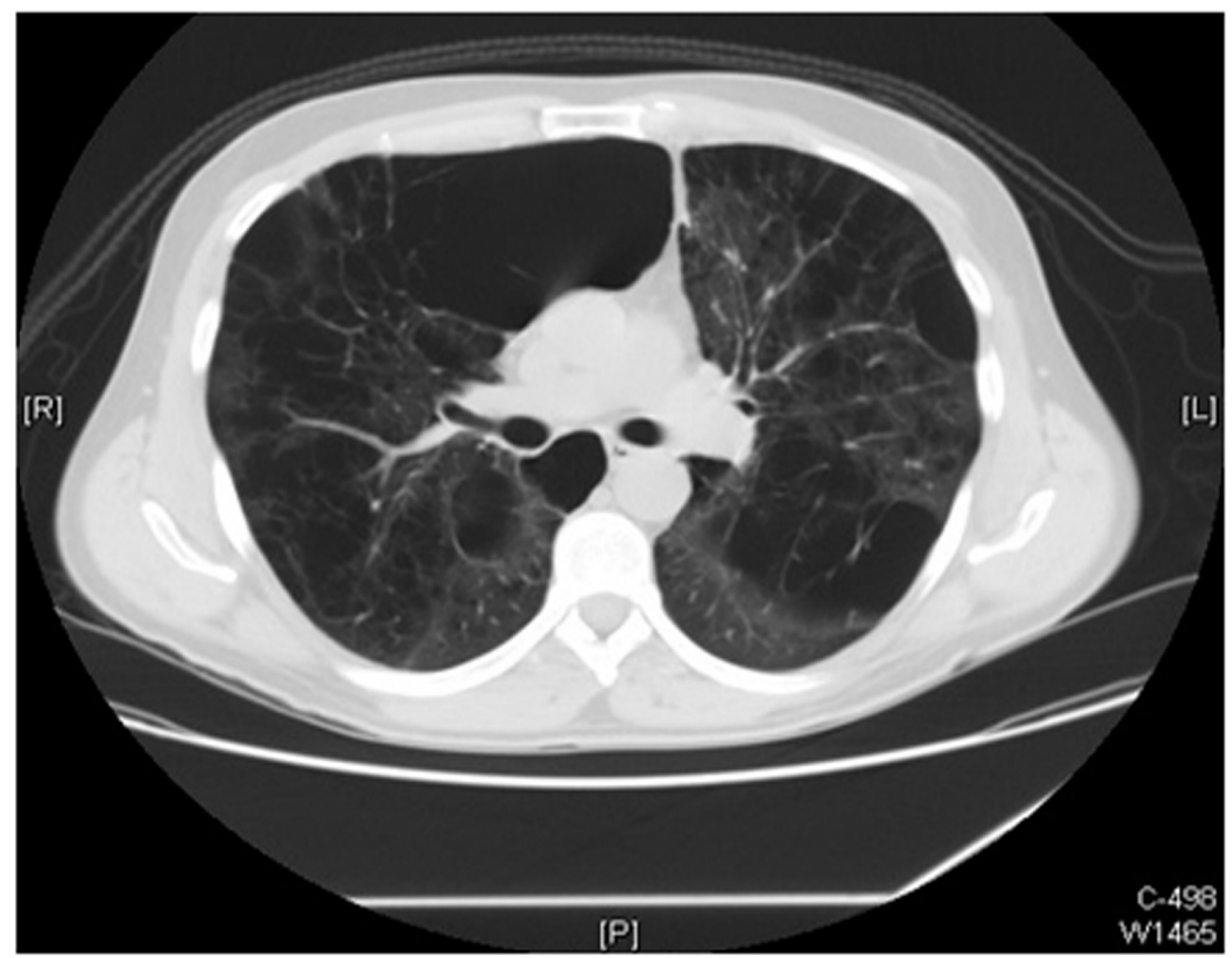

Figure I Panlobular emphysema with multiple bullas.
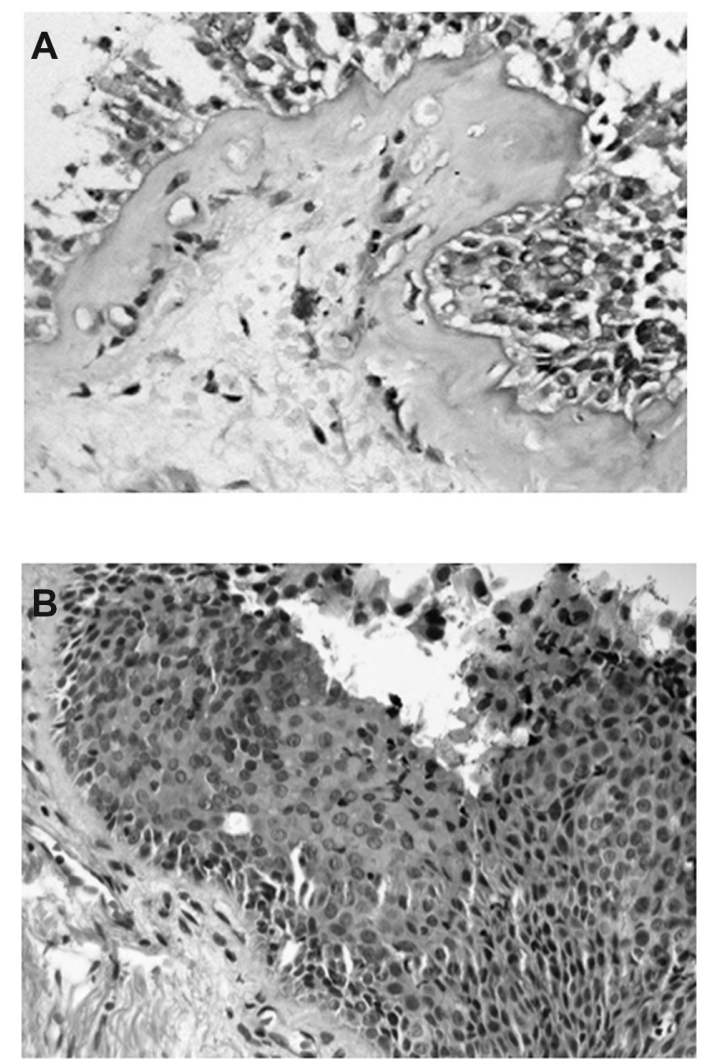

Figure 2 (A) Diffuse thickening of basement membrane $(\geq 6.5 \mu \mathrm{m})$ in irreversible asthma. (PAS stain, $\times 20$ ). (B) Squamous cell metaplasia with epithelial/subepithelial inflammation without thickening of basement membrane $(H / E$ stain, $\times 20)$.
COPD. ${ }^{17,20,21}$ However, the test has two limitations: first, $\mathrm{DL}_{\mathrm{CO}}$ may be normal in early COPD, but it decreases considerably as the disease progresses; ${ }^{21}$ second, in emphysema induced by $\alpha 1$-antitrypsin deficiency (which is limited to the lower lobes, unlike smoker's COPD), $\mathrm{DL}_{\mathrm{CO}}$ may be paradoxically normal. ${ }^{22}$ This is referred to as discordant emphysema. ${ }^{22}$

In conclusion, low $\mathrm{DL}_{\mathrm{CO}}$ is specific to COPD (if bronchiectasis is ruled out by CT scan), but sensitive only in advanced disease. There are no data on the level of advanced disease that lowers $\mathrm{DL}_{\mathrm{CO}}$. In studies on patients with $\mathrm{FEV}_{1} /$ $\mathrm{FVC}$ (forced volume capacity) $<0.70$, there was concurrence between bronchial biopsy indicating COPD and low $\mathrm{DL}_{\mathrm{CO}}$ or $\mathrm{KCO}^{10,13}$ The question is often raised as to why patients with the "chronic bronchitis form" of COPD develop low $\mathrm{DL}_{\mathrm{CO}}$. Should $\mathrm{DL}_{\mathrm{CO}}$ be used as a tool for differentiating the chronic bronchitis (blue bloater) and emphysema (pink puffer) forms of COPD?

\section{The blue bloater and pink puffer types of COPD}

The concept of "blue bloater" COPD without emphysema (and therefore with normal $\mathrm{DL}_{\mathrm{CO}}$ ) is contradicted by pathological studies and CT scans. ${ }^{23,24}$ Although blue bloaters and "pink puffers" present clinical differences, no major 
Table I Characteristics of irreversible asthma and COPD groups (derived from ref 10)

\begin{tabular}{|c|c|c|}
\hline \multirow[t]{4}{*}{ Final Diagnosis } & \multicolumn{2}{|l|}{$\begin{array}{l}\text { Median (IQR) } \\
\text { (range) }\end{array}$} \\
\hline & Irreversible asthma $(n=8)$ & $\operatorname{COPD}(n=16)$ \\
\hline & Presumed irreversible asthma & Presumed COPD (low KCO) \\
\hline & $($ normal KCO) $(n=5)$ & $(n=3)$ \\
\hline \multirow[t]{2}{*}{ Age (years) } & $55(12.5)$ & $67(16)$ \\
\hline & $(42$ to 61$)$ & $(49$ to 70$)$ \\
\hline \multirow[t]{2}{*}{ Age at onset of chronic cough (year) } & $40(19)$ & $49.5(12.7)$ \\
\hline & (22 to 57$)$ & (30 to 60$)$ \\
\hline \multirow[t]{2}{*}{ Age at onset of exercise intolerance/dyspnea (year) } & $45(22)$ & $59(15.5)$ \\
\hline & (9 to 57$)$ & (40 to 66$)$ \\
\hline History of allergic rhinitis & II (84.6\%) & $4(21.1 \%)$ \\
\hline Hypertrophy of nasal turbinates upon examination & $12(92.3 \%)$ & $5(26.3 \%)$ \\
\hline \multirow[t]{2}{*}{ KCO (\% predicted) } & $91.6(10.5)$ & $49.6(20.6)$ \\
\hline & $(81.2$ to 117.6$)$ & (18.7 to 65.3$)$ \\
\hline \multirow[t]{2}{*}{ Change in $\mathrm{FEV}$, following ICS/LABA therapy $(\mathrm{mL})$} & $350(250)$ & $-26.5(84)$ \\
\hline & $(-260$ to 600$)$ & $(-120$ to 91$)$ \\
\hline
\end{tabular}

Abbreviations: ICS, inhaled corticosteroids; LABA, long-acting $\beta 2$-agonists.

differences in the severity of emphysema are revealed by pathological studies at the time of death. ${ }^{23}$ Based on CT scans, COPD cases were divided into Phenotype A (with features of asthma and normal $\mathrm{DL}_{\mathrm{CO}}$ ), Phenotype $\mathrm{M}$ (mixed emphysema/bronchitis), and Phenotype E (emphysema). ${ }^{24}$ Phenotypes $\mathrm{M}$ and $\mathrm{E}$ had low $\mathrm{DL}_{\mathrm{CO}}{ }^{24}$ Studies going back 30 years have used the a priori assumption that if $\mathrm{DL}_{\mathrm{CO}}$ or $\mathrm{DL}_{\mathrm{CO}} / \mathrm{VA}$ is normal, a chronic bronchitis form of COPD is diagnosed without considering that the subjects may be suffering from irreversible asthma. ${ }^{25} \mathrm{~A}$ paper published in 1970 reported that in 45 patients with "obstructive bronchitis" and chronic purulent expectoration (characteristics of the chronic bronchitis type), the $\mathrm{DL}_{\mathrm{CO}}$ was $44.3( \pm 23.7) \%$ predicted. ${ }^{26}$ The authors concluded that " $\mathrm{DL}_{\mathrm{CO}}$ is fixed at a nearly constant low level in obstructive bronchitis ...We regard this as a useful test to differentiate the two diseases (chronic bronchitis and asthma)." ${ }^{26}$ This conclusion was drawn despite the low $\mathrm{DL}_{\mathrm{CO}}$ of some of the patients in the asthmatic group, which is at odds with published reports from as far back as 1970. ${ }^{27}$ This discrepancy may have resulted from the fact that in 1970, it was not appreciated that transient or persistent sputum eosinophilia also occurs in COPD and that its presence does not automatically differentiate between diseases. The asthmatic group in that study (selected on the basis of eosinophilia) may have included a number of eosinophilic COPD patients with low $\mathrm{DL}_{\mathrm{CO}}$.

\section{Why is COPD treated as a second-class condition?}

The tradition of dismissing the possibility of irreversible asthma persists. In a large study published in 2007 ,
105 out of 307 COPD patients had no or little emphysema on HRCT scan. ${ }^{28}$ The possibility that some of these patients might have been asthmatic was dismissed by excluding subjects who were diagnosed by their physicians as having asthma and by the absence of $\mathrm{FEV}_{1}$ reversibility upon inhaling $400 \mu \mathrm{cg}$ albuterol. ${ }^{28}$ Acute reversibility tests fail to differentiate between asthma and COPD; ${ }^{29}$ however, the long-term fluctuation of $\mathrm{FEV}_{1}$ in response to therapy with inhaled corticosteroids shows promising results. ${ }^{10}$ GOLD has also taken the position that "the degree of reversibility has never been shown to add to the diagnosis or differential diagnosis with asthma." ${ }^{\prime}$ Lung biopsy, diffusion studies and CT scans are widely advocated in cases of interstitial lung disease and have resulted in great strides in the classification and management of that condition. We would like this review to generate a discussion about why these techniques are not advocated in COPD (which we prefer to call "chronic airflow limitation" until fully investigated). Irreversible asthma is not the only concern. Bronchiectasis is sometimes a common concomitant or alternative diagnosis in COPD cases. ${ }^{30}$ The prevalence of bronchiectasis is highest in cases of moderate or severe COPD (up to $57 \%$, but much less in most other studies) and is associated with bacterial colonization and a higher frequency of exacerbation..$^{31}$ The association between the two conditions is so strong that some researchers have speculated that severe COPD is a predisposing factor for bronchiectasis. ${ }^{32}$ It is also possible that cases that are diagnosed as COPD began as bronchiectasis with irreversible airway obstruction and reduced diffusing capacity. 


\section{Phenotyping}

Although phenotyping and clustering according to clinical characteristics (including airway reversibility) has clearly shown the heterogeneous nature of COPD, considerable overlap exists between these clusters. Phenotyping, both with cytology and CT scan, will be discussed.

\section{Phenotyping with cytology}

The cellular infiltrate in COPD has been studied in bronchial tissue, bronchoalveolar lavage, and sputum samples. Although discrepancies have been recorded in the percentage of cells, both techniques show similar overall cellularity trends. Eosinophil counts, in particular, show good agreement when determined using the three techniques. ${ }^{33}$ The cellular infiltrate in stable COPD shows increased numbers of neutrophils, macrophages, lymphocytes, and occasionally, eosinophils. However, neutrophils and eosinophils have attracted the most attention. Bronchial biopsies and induced sputum have consistently shown a correlation between the severity of airway obstruction and neutrophil count. ${ }^{34}$

In normal subjects, eosinophils account for less than 3\% of the cells in induced sputum (usually less than 1\%). In stable COPD, $20 \%$ to $40 \%$ of patients show increased eosinophil levels in sputum. ${ }^{35-37}$ Although eosinophils surge by 0.5 - to 30 -fold during exacerbations, they account, on average, for less than $5 \%$ of sputum cells; in contrast, neutrophils account for more than $70 \%$ of sputum cells. ${ }^{36,38,39}$ This may explain why prednisolone has a modest effect on expediting recovery in acute exacerbations.

\section{Significance of "eosinophilic COPD"}

It is tempting to speculate that the $20 \%$ to $40 \%$ of stable COPD subjects with "eosinophilic bronchitis" are instead cases of irreversible asthma. Barnes and Barnes speculated that such cases represent an asthmatic component in the COPD syndrome or concomitant asthma and COPD, although other researchers have offered alternative explanations..$^{40-42}$ The views of Barnes and Barnes may be supported by the response of "eosinophilic COPD" to corticosteroids. Prednisolone produced a significant increase of $\mathrm{FEV}_{1}$ values and shuttle distance only in COPD patients who had sputum eosinophilia exceeding $3 \% .^{37,42,43}$ In another study, sputum eosinophilia was associated with higher Interleukin-5 in sputum and a positive response to oral prednisolone. ${ }^{44}$ Similarly, ICS produced a modest but significant increase in $\mathrm{FEV}_{1}$ and Chronic Respiratory Questionnaire scores only in patients with sputum eosinophilia (Figure 3). ${ }^{35,45}$
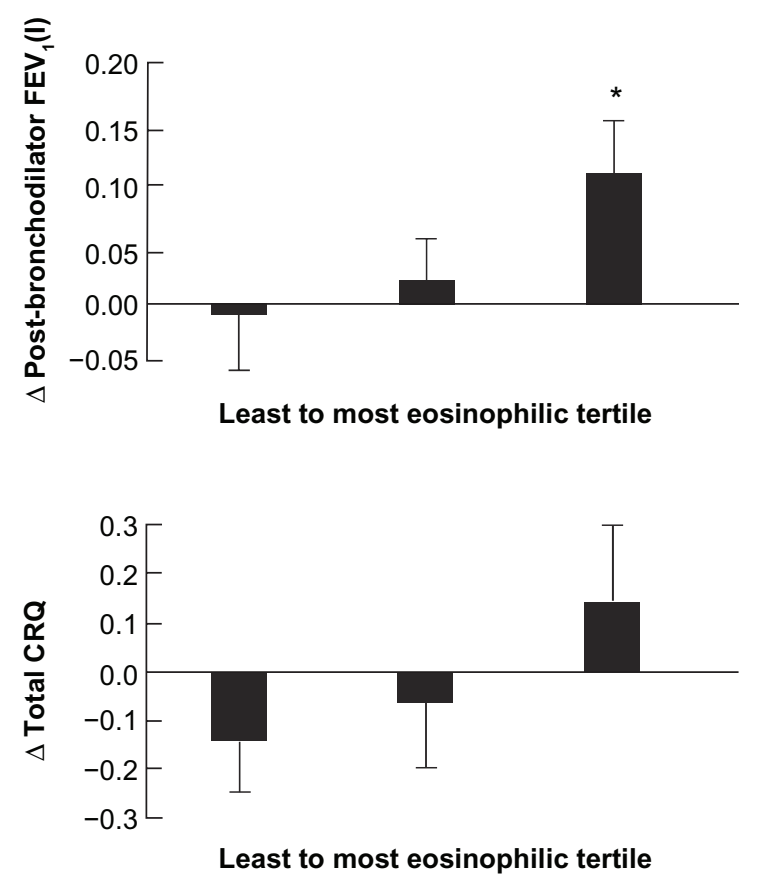

Figure 3 Absolute increase in post-bronchodilator $\left(\mathrm{FEV}_{1}\right)$ and total Chronic Respiratory Disease Questionnaire (CRQ) score after mometasone compared with placebo for each tertile of sputum eosinophilia. Reprinted from Brightling CE, McKenna S, Hargadon B, et al. Sputum eosinophilia and the short term response to inhaled mometasone in chronic obstructive pulmonary disease. Thorax. 2005;60(3): 193-198.45 @ with permission BMJ 2005.

Note: $* P<0.05$ (paired/test).

Although several studies have shown a marginal reduction of neutrophils or total cells in response to ICS, a large number of studies have found no such effect on inflammatory cells or markers. ${ }^{42,45-52}$ Some studies have shown that inhaled corticosteroids reduce eosinophils, while other studies have failed to produce such results. ${ }^{35,45,50-52}$ Oral prednisolone, in contrast, has been shown to generally reduce eosinophils in sputum. ${ }^{37,43}$ These findings further support the mounting evidence that COPD (apart from the eosinophilic cases) is not steroid responsive and that the delivery of inhalers to terminal bronchioles and alveoli is inadequate to suppress eosinophils in a consistent manner.

\section{Phenotyping via CT scan}

\section{Phenotyping using CT attenuation scores}

The "emphysema index" is measured as the percentage of lung area with $\mathrm{CT}$ attenuation (-820 to -950 Hounsfield units $=\mathrm{HU})$. This scoring method can be computerized or visual. Although quantitative computerized scoring of emphysema has greatly advanced our understanding of COPD, it has a serious drawback. It interprets any increased attenuation of the lungs (whether caused by hyperinflation as in asthma or emphysematous destruction of alveolar walls) 
as emphysema. Severe asthma is a particular area of overlap. Based on computerized CT scores, the mean value of the lowest fifth percentile of CT lung density was -912 HU in nonsmoking asthmatics and $-942 \mathrm{HU}$ in COPD patients. ${ }^{53}$

\section{CT measurement of airway thickening}

Airway thickening can be measured with CT scans. It is usually expressed as wall area percentage (WA \%) and has been found to correlate with $\mathrm{FEV}_{1}$ and residual volume/total lung capacity (RV/TLC), but not $\mathrm{DL}_{\mathrm{CO}}{ }^{54}$ Patients with chronic bronchitis symptoms are more likely to have greater airway thickening than those who have similar airway obstruction but no symptoms. ${ }^{55}$ Although the bronchial changes of COPD occur predominantly in the small airways, the presence of "surrogate" changes in large airways ensures the usefulness of WA \% in diagnosing bronchitis. ${ }^{56}$ Airway thickening is not synonymous with chronic bronchitis as a pathological diagnosis. Both irreversible asthma and COPD produce airway thickening, and no cut-off level can distinguish between them. ${ }^{17,57,58}$

\section{Visual qualitative assessment of CT scans}

This is achieved by inspecting the CT scans for qualitative changes like bullas size and distribution or the degree of attenuation and branching of blood vessels. Table 2 summarizes the visual qualitative differences between asthma and COPD and explains why radiologists may report "emphysema" in asthmatics who have never smoked.

Examination of Table 2 makes it clear that panlobular emphysema is the only specific radiological sign of COPD. Widespread centrilobular emphysema or multiple bullas imply the presence of COPD, provided that the observer is aware that the same changes, if limited, can be caused by either asthma or COPD. ${ }^{59-63}$ In smoking-induced COPD, centrilobular emphysema is more common (two-thirds of patients) than pan-

Table 2 Qualitative CT scan changes in asthma and COPD (compiled by the authors)

\begin{tabular}{|c|c|c|}
\hline & Asthma & COPD \\
\hline $\begin{array}{l}\text { Wide branching } \\
\text { and thinning } \\
\text { of blood vessels }\end{array}$ & May be present & Common \\
\hline $\begin{array}{l}\text { Centrilobular } \\
\text { or paraseptal } \\
\text { emphysema }\end{array}$ & $\begin{array}{l}\text { Occasionally described } \\
(0 \%-10 \%) \text {; usually } \\
\text { limited }^{59,60}\end{array}$ & $\begin{array}{l}\text { Common and usually } \\
\text { diffuse }\end{array}$ \\
\hline $\begin{array}{l}\text { Panlobular } \\
\text { emphysema }\end{array}$ & Never described & $\begin{array}{l}\text { Common (more in I- } \alpha \text { - } \\
\text { antitrypsin deficiency than } \\
\text { in smoker's COPD) }{ }^{64}\end{array}$ \\
\hline Bullas & $\begin{array}{l}\text { Rare/anecdotal reports; } \\
\text { usually single }\end{array}$ & Common \\
\hline
\end{tabular}

lobular emphysema (one-third of patients). ${ }^{64}$ Panlobular emphysema is the predominant form in $\alpha 1$-antitrypsin deficiency.

\section{CT scans split "COPD” into asthma} and two types of COPD proper

Data with startling practical implications have been reported. Using visual evaluation of HRCT scans, Fujimota et al classified COPD patients into three phenotypes: absent or little emphysema (Phenotype A), emphysema with bronchial thickening (Phenotype M), and emphysema without bronchial wall thickening (Phenotype E). ${ }^{24}$ Phenotype A included 18\% of never-smokers, and it was characterized by normal $\mathrm{DL}_{\mathrm{CO}}$ and significant responsiveness to $\beta-2$ agonists. ${ }^{24}$ Fujimoto concluded that the majority of patients with Phenotype A are asthmatic. ${ }^{24}$ Phenotype $\mathrm{M}$ was associated with a clinical picture of chronic bronchitis, low $\mathrm{DL}_{\mathrm{CO}}$, responsiveness to $\beta$-2 agonists, and higher rates of exacerbation and hospitalization. ${ }^{24}$ Phenotype E had even lower $\mathrm{DL}_{\mathrm{CO}}$ and no significant responsiveness of $\mathrm{FEV}_{1} \cdot{ }^{24}$

Using visual quantitative grading of CT scans from the Boston early-onset COPD study, Hersh et al found that the group with the least emphysema (scores of 0-6 out of 24) had asthma-like features. ${ }^{65}$ The mean $\mathrm{FEV}_{1}$ in that group was $22.4 \%$ predicted, which shows that severe obstruction can occur with irreversible asthma. ${ }^{65}$ In 2009, Lee et al reported that the emphysema-dominant subtype showed no improvement of $\mathrm{FEV}_{1}$ or dyspnea after three months of treatment with salmeterol/fluticasone or formoterol/budesonide. ${ }^{66}$

COPD is not a single disease that can be treated with the same drugs regardless of phenotype. It includes asthma, mixed bronchitis/emphysema COPD, and emphysema-dominant COPD (which Fujimoto referred to as Phenotypes A, M, and E). ${ }^{24}$ When phenotyping is applied (eg, bronchial histology, CT scan, sputum eosinophilia, or $\mathrm{DL}_{\mathrm{CO}}$ ), different patterns of responsiveness to corticosteroids are elicited. ICS withdrawal results in no decline of $\mathrm{FEV}_{1}$ or FVC in COPD patients with panlobular emphysema, bronchial biopsy indicating COPD, or low KCO. ${ }^{67}$ The controversy over the role of ICS in COPD was attributed to the fact that we are attempting to treat two different conditions with the same drug regimen. ${ }^{68}$

\section{Revolution and counterrevolution: the rise and fall of the "overlap syndrome" of COPD and asthma Overview of the overlap syndrome}

Phenotyping is truly a revolution. By demonstrating that the response to inhaled corticosteroids is restricted to one 
phenotype with asthmatic features, phenotyping promises targeted, and less costly treatments for COPD. This is at odds with the newly coined overlap syndrome that merges asthma into COPD, and more importantly, has prompted some authors to recommend a multidrug approach that targets both conditions. Some authors have recommended that, in addition to inhaled corticosteroids, long-acting $\beta$ - 2 agonists, and longacting muscarinic antagonists, "adjunctive treatments such as leukotriene receptor antagonists, 5-lipoxygenase inhibitors, methylxanthines, or omalizumab deserve further study and should be administered by pulmonary subspecialists." ${ }^{69}$

\section{Definition(s) and prevalence of the overlap syndrome}

There is no consensus on a clear definition for the overlap syndrome. ${ }^{69}$ Some authors have used patients' reports of receiving an asthma diagnosis before the age of 40 years or without any age restriction. ${ }^{70}$ Others have used the presence of variable but incompletely reversible airflow

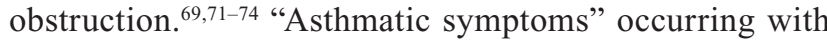
COPD, such as episodic breathlessness, wheezing, cough, or chest tightness worsening at night, were also considered diagnostic of the overlap syndrome. ${ }^{75,76}$ Sputum eosinophilia or history of atopy were also listed as criteria for diagnosis. ${ }^{69,74}$ Some of the authors who advocate the overlap syndrome have recognized the lack of specificity of criteria based on spirometry or symptoms. ${ }^{69}$ Nevertheless, other authors have concluded that the overlap syndrome has been "confirmed by objective testing." 71 The study they quote in support of their theory was highly valuable in showing the heterogeneity of obstructive lung disease, but failed to prove the overlap of asthma and COPD, as it used the same criteria that lacked specificity. ${ }^{77}$ For instance, cough and sputum production, which were used to diagnose chronic bronchitis, are more likely to be caused by asthma, especially asthma associated with rhinitis. ${ }^{78}$ Even excessive sputum production is more commonly caused by postnasal drip syndrome or asthma than by bronchitis. ${ }^{79}$ Similarly, centrilobular and paraseptal emphysema have been described in asthma. ${ }^{59,60}$ Furthermore, significant post bronchodilator response is well described in COPD, especially in the combined emphysema-bronchitis phenotype. ${ }^{24,80}$ Using these arbitrary criteria, the reported prevalence of the overlap syndrome was $13 \%$ to $21 \%$ of COPD patients. ${ }^{69,70}$ Some studies found that patients in the overlap group were the same age as those in the COPD group, but other studies reported that patients in the overlap group were younger. ${ }^{69,70,75}$ The syndrome has even been reported in patients in their thirties. ${ }^{69}$

\section{Drug management of the overlap syndrome}

Concerns that a multidrug approach to therapy is necessary to manage the overlap syndrome have not been proven. The only study so far (until June 2012) that has examined the therapeutic response of the overlap syndrome reported that the response to inhaled corticosteroids was significantly correlated with sputum eosinophilia and bronchial wall thickening. ${ }^{75}$ Both features are known to be associated with irreversible asthma. ${ }^{13,17}$ Back to basics: phenotyping, and not overlap syndrome, determine the response to ICS. This supports our speculation that what is referred to as overlap syndrome consists of separate cases of asthma and COPD, selected for longer illness (asthma diagnosed under the age of 40) and more labile disease (variable airflow obstruction), which explains the significant association with more frequent and severe exacerbations and worse disease-related quality of life. ${ }^{70,81}$

\section{Are we dealing with a "syndrome" or a "non-syndrome"?}

The tide may be turning back against the overlap syndrome. In the first half of 2012, PubMed listed only two publications on the asthma and COPD overlap syndrome. One of these is the Kitaguchi paper, which reports on the association between eosinophilia and the response to ICS. ${ }^{75}$ Compare those two results with 56 results for a search on "phenotyping and COPD." The phenotype and overlap syndrome approaches are incompatible. One aims at splitting, while the other aims at merging the various strands of COPD. More importantly, phenotyping predicts response to ICS, while the only study that tested the overlap syndrome found that the syndrome (not surprisingly) split into steroid-responsive and unresponsive groups ${ }^{75}$ The overlap syndrome has all the features of a non-syndrome, ie, arbitrary definitions that defy published evidence and on which there is no agreement, heterogeneous features, the inability to be defined by such objective tests as histology or CT scan, and a lack of uniform response to therapy.

\section{Practical diagnostic approach to irreversible airway limitation in smokers}

1. All patients should receive a full pulmonary function test. A diagnosis of COPD is made in the presence of low KCO or hypercapneic respiratory failure with raised serum bicarbonate. Attention should be paid to the fact that $\mathrm{CO}$ diffusion studies may be reduced in pulmonary edema, and that hypercapneic respiratory failure may be 
the result of obesity hypoventilation syndrome. However, these are generally clinically overt conditions that are not easily missed.

2. If pulmonary function tests do not support a diagnosis of COPD, fiberoptic bronchial biopsy (3rd order bronchus) should be offered. Common experience and published evidence indicate the lack of mortality or serious side effects with endobronchial biopsy in patients free of respiratory failure and coagulation disorders. The average pathologist should review the recent publications on the histology of irreversible asthma and COPD before reporting the specimens.

3. CT scan of the lungs should be ordered in patients who refuse bronchoscopy. A pattern of panlobular or widespread centrilobular emphysema is diagnostic of COPD. Hyperinflation with attenuation of blood vessels is not conclusive and $\mathrm{CO}$ diffusion studies would favor either asthma or COPD.

4. CT scan of the lungs should be performed in any patient with moderate or severe airway obstruction if associated with abundant purulent sputum to exclude bronchiectasis.

\section{Conclusion}

What is currently defined as COPD consists of irreversible asthma and COPD proper. The COPD entity is subdivided further into mixed bronchitis/emphysema (Phenotype M) and predominantly emphysema (Phenotype E). Irreversible asthma and COPD can be differentiated by $\mathrm{CO}$ diffusion studies and bronchial biopsy. Additionally, a CT scan showing widespread panlobular or centrilobular emphysema (by visual qualitative inspection) is diagnostic of COPD. However, the computerized emphysema score, which reads the degree of lung attenuation, overlaps in irreversible asthma and COPD. Patients with moderate or severe airway obstruction producing copious or purulent sputum may be suffering from bronchiectasis.

Response to corticosteroids is limited to irreversible asthma and when eosinophilia is documented in the sputum. The overlap syndrome has all the features of a non-syndrome, including the absence of any agreement about how to define it and the lack of uniform response of ICS.

\section{Acknowledgments}

Both authors of this review devised the original plan and contributed to its writing. Both authors approved the final draft and its revision.

\section{Disclosure}

No funds were sought or obtained. The authors report no conflicts of interest in this work.

\section{References}

1. Global Initiative for Chronic Obstructive Pulmonary Disease. Updated 2010. Available from: http://www.goldcopd.org. Accessed September 15, 2012.

2. Tsuda Y, Noguchi T, Mochizuki H, et al. Patients with mild-to-moderate asthma may develop clinically significant chronic obstructive pulmonary disease. Respirology. 2009;14(4):529-536.

3. Bellia V, Battaglia S, Catalano F, et al. Aging and disability affect misdiagnosis of COPD in elderly asthmatics: the SARA study. Chest. 2003;123(4):1066-1072.

4. Ulrik CS, Backer V. Nonreversible airflow obstruction in life-long nonsmokers with moderate to severe asthma. Eur Respir J. 1999; 14(4):892-896

5. ten Brinke A: Risk factors associated with irreversible airflow limitation in asthma. Curr Opin Allergy Clin Immunol. 2008;8(1):63-69.

6. Dik N, Anthonisen NR, Manfreda J, Roos LL. Physician-diagnosed asthma and allergic rhinitis in Manitoba: 1985-1998. Ann Allergy Asthma Immunol. 2006;96(1):69-75.

7. Hwang CY, Chen YJ, Lin MW, et al. Prevalence of atopic dermatitis, allergic rhinitis and asthma in Taiwan: a national study 2000 to 2007. Acta Derm Venereol. 2010;90(6):589-594.

8. Gillman A, Douglass JA. Asthma in the elderly. Asia Pac Allergy. 2012;2(2):101-108.

9. Chanez P, Vignola AM, O'Shaugnessy T, et al. Corticosteroid reversibility in COPD is related to features of asthma. Am J Respir Crit Care Med. 1997;155(5):1529-1534.

10. Al-Kassimi FA, Abba AA, Al-Hajjaj MS, et al. Asthma masquerading as chronic obstructive pulmonary disease: A study of smokers fulfilling the GOLD definition of chronic obstructive pulmonary disease. Respiration. 2011;82(1):19-27.

11. Bourdin A, Serre I, Flamme A, et al. Can endobronchial biopsy analysis be recommended to discriminate between asthma and COPD in routine practice? Thorax. 2004;59(6):488-493.

12. Liesker JJ, Ten Hacken NH, Zeinstra-Smith M, Rutgers SR, Postma DS, Timens W. Reticular basement membrane in asthma and COPD: similar thickness, yet different composition. Int J Chron Obstruct Pulmon Dis. 2009;4:127-135.

13. Fabbri LM, Romagnoli M, Corbetta L, et al. Differences in airway inflammation in patients with fixed airflow obstruction due to asthma or chronic obstructive pulmonary disease. Am J Respir Crit Care Med. 2003;167(3):418-424.

14. Tagaya E, Tamaoki J. Mechanisms of airway remodeling in asthma. Allergol Int. 2007;56(4):331-340.

15. Boulet LP, Turcotte H, Hudon C, et al. Clinical, physiological and radiological features of asthma with incomplete reversibility compared with those of COPD. Can Respir J. 1998;5(4):270-277.

16. Mitsunobu F, Mifune T, Ashida K, et al. Influence of age and disease severity on high resolution CT lung densitometry in asthma. Thorax. 2001;56(11):851-856.

17. Simpson JL, Milne DG, Gibson PG. Neutrophilic asthma has different radiographic features to COPD and smokers. Respir Med. 2009;103(6):881-887.

18. Frans A, Nemery B, Veriter C, Lacquet L, Francis C. Effect of alveolar volume on the interpretation of single breath DLCO. Respir Med. 1997;91(5):263-273.

19. D'Anna SE, Asnaghi R, Caramori G, et al. High-resolution computed tomography quantitation of emphysema is correlated with selected lung function values in stable COPD. Respiration. 2012;83(5):383-390.

20. Magnussen H, Richter K, Taube C. Are chronic obstructive pulmonary disease (COPD) and asthma different diseases? Clin Exp Allergy. 1998;28S(5):187-194. 
21. Goedhart DM, Zanen P, Lammers JW. Relevant and redundant lung function parameters in discriminating asthma from COPD. COPD. 2006;3(1):33-39.

22. Holme J. Stockley RA. Radiology and clinical features of COPD patients with discordant pulmonary physiology. Lessons from $\alpha 1$-antitrypsin deficiency. Chest. 2007;132(3):909-915.

23. Mitchell RS, Stanford RE, Johnson JM, Silvers GW, Dart G, George MS. The morphologic features of the bronchi, bronchioles, and alveoli in chronic airway obstruction: a clinicopathologic study. Am Rev Respir Dis. 1976;114(1):137-145.

24. Fujimoto K, Kitaguchi Y, Kubo K, Honda T. Clinical analysis of chronic obstructive pulmonary disease phenotypes classified using highresolution computed tomography. Respirology. 2006;11(6):731-740.

25. Openbrier DR, Irwin MM, Rogers RM, et al. Nutritional status and lung function in patients with emphysema and chronic bronchitis. Chest. 1983;83(1):17-22.

26. Palmer KNV, Diament ML. A comparison of pulmonary function in bronchial asthma and chronic obstructive bronchitis. Thorax. 1970;25(1):101-104.

27. Meisner P, Hugh-Jones P. Pulmonary function in bronchial asthma. BMJ. 1968;1(5590):470-475.

28. Makita H, Nasuhara Y, Nagai K, et al. Characterisation of phenotypes based on severity of emphysema in chronic obstructive pulmonary disease. Thorax. 2007;62(11):932-937.

29. Chhabra SK. Acute bronchodilator response has limited value in differentiating bronchial asthma from COPD. J Asthma. 2005;42(5):367-372.

30. Patel IS, Vlahos I, Wilkinson TM, et al. Bronchiectasis, exacerbation indices, and inflammation in chronic obstructive pulmonary disease. Am J Respir Crit Care Med. 2004;170(4):400-407.

31. Martinez-Garcia MA, Soler-Cataluña JJ, Donat-Sanz Y, et al. Factors associated with bronchiectasis in patients with chronic obstructive pulmonary disease. Chest. 2011;140(5):1130-1137.

32. Garcia MA, Catalüna JJ. Chronic Obstructive Pulmonary disease and bronchiectasis. Arch Bronconeumol. 2010;46S(3):11-17.

33. Maestrelli P, Saetta M, Di Stefano A, et al. Comparison of leukocyte counts in sputum, bronchial biopsies, and bronchoalveolar lavage. Am J Respir Crit Care Med. 1995;152(6 Pt 1):1926-1931.

34. Stănescu D, Sanna A, Veriter C, et al. Airways obstruction, chronic expectoration, and rapid decline of $\mathrm{FEV}_{1}$ in smokers are associated with increased levels of sputum neutrophils. Thorax. 1996;51(3):267-271.

35. Leigh R, Pizzichini MMM, Morris MM, et al. Stable COPD: predicting benefit from high-dose inhaled corticosteroid treatment. Eur Respir J. 2006;27(5):964-971.

36. Saetta M, Di Stefano A, Maestrelli P, et al. Airway eosinophilia in chronic bronchitis during exacerbations. Am J Respir Crit Care Med. 1994;150(6 Pt 1):1646-1652.

37. Brightling CE, Monteiro W, Ward R, et al. Sputum eosinophila and short-term response to prednisolone in chronic obstructive pulmonary disease: a randomized controlled trial. Lancet. 2000;356(9240) 1480-1485.

38. Fujimoto K, Yasuo M, Urushibata K, Hanaoka M, Koizumi T, Kubo K. Airway inflammation during stable and acutely exacerbated chronic obstructive pulmonary disease. Eur Respir J. 2005;25(4):640-646.

39. Bathoorn E, Liesker JJW, Postma DS, et al. Change in inflammation in out-patient COPD patients from stable phase to a subsequent exacerbation. Int J Chron Obstruc Pulmon Dis. 2009;4:101-109.

40. Barnes NC. Inhaled steroids in COPD. Lancet. 1998;351(9105): 766-767.

41. Barnes PJ, Shapiro SD, Pauwels RA. Chronic obstructive pulmonary disease: molecular and cellular mechanisms. Eur Respir J. 2003;22(4):672-688

42. Saha S, Brightling CE. Eosinophilic airway inflammation in COPD. Int J Chron Obstruc Pulmon Dis. 2006;(1):39-47.

43. Fujimoto K, Kubo K, Yamamoto H, Yamaguchi S, Matsuzawa Y. Eosinophilic inflammation in the airway is related to glucocorticoid reversibility in patients with pulmonary emphysema. Chest. 1999;115(3):697-702.
44. Bafadhel M, Saha S, Siva R, et al. Sputum IL-5 concentration is associated with a sputum eosinophilia and attenuated by corticosteroid therapy in COPD. Respiration. 2009;78(3):256-262.

45. Brightling CE, McKenna S, Hargadon B, et al. Sputum eosinophilia and the short term response to inhaled mometasone in chronic obstructive pulmonary disease. Thorax. 2005;60(3):193-198.

46. Keatings VM, Jatakanon A, Worsdell YM, Barnes PJ. Effects of inhaled and oral glucocorticoids on inflammatory indices in asthma and COPD. Am J Respir Crit Care Med. 1997;155(2):542-548.

47. Culpitt SV, Maziak W, Loukidis S, Nightingale JA, Matthews JL, Barnes PJ. Effect of high dose inhaled steroid on cells, cytokines, and proteases in induced sputum in chronic obstructive pulmonary disease. Am J Respir Crit Care Med. 1999;160(5 Pt 1):1635-1639.

48. Loppow D, Schleiss MB, Kanniess F, Taube C, Jörres RA, Magnussen H. In patients with chronic bronchitis a four week trial with inhaled steroids does not attenuate airway inflammation. Respir Med. 2001;95(2): $115-121$.

49. Gizycki MJ, Hattotuwa KL, Barnes N, Jeffery PK. Effects of fluticasone propionate on inflammatory cells in COPD: an ultrastructural examination of endobronchial biopsy tissue. Thorax. 2002;57(9):799-803.

50. Hattotuwa KL, Gizycki MJ, Ansari TW, Jeffery PK, Barnes NC. The effects of inhaled fluticasone on airway inflammation in chronic obstructive pulmonary disease: a double-blind, placebo-controlled biopsy study. Am J Respir Crit Care Med. 2002;165(12):1592-1596.

51. Bathoorn E, Liesker JJ, Postma DS, et al. Anti-inflammatory effects of combined budesonide/formoterol in COPD exacerbations. COPD. 2008;5(5):282-290.

52. Confalonieri M, Mainardi E, Della Porto R, et al. Inhaled corticosteroids reduce neutrophilic bronchial inflammation in patients with chronic obstructive pulmonary disease. Thorax. 1998;53(7):583-585.

53. Biernacki W, Redpath AT, Best JJ, MacNee W. Measurement of CT lung density in patients with chronic asthma. Eur Respir J. 1997; 10(11):2455-2459.

54. Nakano Y, Muro S, Sakai H, et al. Computed tomographic measurements of airway dimensions and emphysema in smokers. Correlation with lung function. Am J Respir Crit Care Med. 2000;162(3 Pt 1):1102-1108.

55. Orlandi I, Moroni C, Camiciottoli G, et al. Chronic obstructive pulmonary disease: thin-section CT measurement of airway wall thickness and lung attenuation. Radiology. 2005;234(2):604-610.

56. Nakano Y, Wong JC, de Jong PA, et al. The prediction of small airway dimensions using computed tomography. Am J Respir Crit Care Med. 2005;171(2):142-146.

57. Kosciuch J,Krenke R, Gorska K, Zukowska M, Maskey-Warzechowska M, Chazan R. Relationship between airway wall thickness assessed by high-resolution computed tomography and lung function in patients with asthma and chronic obstructive pulmonary disease. $J$ Physiol Pharmacol. 2009;60 Suppl 5:71-76.

58. Nakano Y, Van Tho N, Yamada H, Osawa M, Nagao T. Radiological approach to asthma and COPD - the role of computed tomography. Allergol Int. 2009;58(3):323-331.

59. Harmanci E, Kebapci M, Metintas M, et al. High-resolution computed tomography findings are correlated with disease severity in asthma. Respiration. 2002;69(5):420-426.

60. Gupta S, Siddiqui S, Haldar P, et al. Qualitative analysis of high-resolution CT scans in severe asthma. Chest. 2009;136(6):1521-1528.

61. Kusaka T, Go M, Ohkubo T, et al. A case of middle lobar bulla associated with severe bronchial asthma. Kyobu Geka. 1992;45(3):279-282.

62. Ishikawa S, Yoshida I, Otaki A, et al. Surgical treatments of emphysematous giant bullae accompanied with severe bronchial asthma. Kyobu Geka. 1992;45(10):895-899.

63. Nakamura S, Matsumura A, Hashimoto Y, Kawakami M. Intrabullar suction-adhesion in a case of giant bulla of the lung with steroiddependent intractable bronchial asthma. Nihon Kyobu Shikkan Gakkai Zasshi. 1994;32(11):1115-1119.

64. Gupta PP, Yadav R, Verma M, et al. High-resolution computed tomography features in patients with chronic obstructive pulmonary disease. Singapore Med J. 2009;50(2):193-200. 
65. Hersh CP, Jacobson FL, Gill R, Silverman EK. Computed tomography phenotypes in severe, early-onset chronic obstructive pulmonary disease. COPD. 2007;4(4):331-337.

66. Lee JH, Lee YK, Kim EK, et al. Responses to inhaled long-acting betaagonist and corticosteroid according to COPD subtype. Respiratory Medicine. 2010;104(4):542-549.

67. Al-Kassimi FA, Al-Hajjaj MS, Alhamad ES, et al. Abrupt withdrawal of inhaled corticosteroids in COPD does not produce spirometric deterioration: role of phenotyping. Ann Thoracic Med. 2012;7(4):238-242.

68. Al-Kassimi FA, Alhamad EH. Chronic obstructive pulmonary disease lost in translation: why are the inhaled corticosteroids skeptics refusing to go. Ann Thoracic Med. 2013. In press.

69. Zeki AA, Schivo M, Chan A, Albertson TE, Louie S. The asthma COPD overlap syndrome: A common clinical problem in the elderly. J Allergy (Cairo). 2011;2011:Article ID 861926.

70. Hardin M, Silverman EK, Barr RG, et al. The clinical features of the overlap between COPD and asthma. Respir Res. 2011;12:127.

71. Kim SR, Rhee YK. Overlap between asthma and COPD: where the two diseases converge. Allergy Asthma Immunol Res. 2010;2(4):209-214.

72. Plusa T. Overlap syndrome - asthma and chronic obstructive pulmonary disease. Pneumonol Alergol Pol. 2011;79(5):351-356.

73. Gibson PG, Simpson JL. The overlap syndrome of asthma and COPD: what are its features and how important is it? Thorax. 2009;64(8): $728-735$.
74. Soler-Cataluña JJ, Cosio B, Izquierdo JL, et al. Consensus document on the overlap phenotype COPD-asthma in COPD. Arch Bronconeumol. 2012;48(9):331-337.

75. Kitaguchi Y, Komatsu Y, Fujimoto K, Hanaoka M, Kubo K. Sputum eosinophilia can predict responsiveness to inhaled corticosteroid treatment in patients with overlap syndrome of COPD and asthma. Int $J$ Chron Obstruct Pulmon Dis. 2012;7:283-289.

76. Miravitlles M, Calle M, Soler-Cataluña JJ. Clinical phenotypes of COPD: identification, definition and implications for guidelines. Arch Bronchoneumol. 2012;48(3):86-98.

77. Marsh SE, Travers J, Weatherall M, et al. Proportional classifications of COPD phenotypes. Thorax. 2008;63(9):761-767.

78. Lu GL, Lin JT. The spectrum and clinical features of causes for chronic cough. Zhonghua Jie He He Hu Xi Za Zhi. 2009;32(6):422-425.

79. Smyrnios NA, Irwin RS, Curley FJ. Chronic cough with history of excessive sputum production. The spectrum and frequency of causes, key components of the diagnostic evaluation, and outcome of specific therapy. Chest. 1995;108(4):991-997.

80. Tashkin DP, Celli B, Decramer M. et al. Bronchodilator responsiveness in patients with COPD. Eur Respir J. 2008;31(4):742-750.

81. Kauppi P, Kupiainen H, Lindqvist A, et al. Overlap syndrome of asthma and COPD predicts low quality of life. J Asthma. 2011;48(3): 279-285.

\section{Publish your work in this journal}

The International Journal of COPD is an international, peer-reviewed journal of therapeutics and pharmacology focusing on concise rapid reporting of clinical studies and reviews in COPD. Special focus is given to the pathophysiological processes underlying the disease, intervention programs, patient focused education, and self management protocols.

\section{Dovepress}

This journal is indexed on PubMed Central, MedLine and CAS. The manuscript management system is completely online and includes a very quick and fair peer-review system, which is all easy to use. Visit http://www.dovepress.com/testimonials.php to read real quotes from published authors. 